\title{
Messi gana el partido y logra registrar su marca en la Unión Europea
}

\section{Sentencia del Tribunal de Justicia de 17 de septiembre de 2020 (C-449/18 P; C-474/18 P)}

\author{
$* * * *$ \\ Jesús Gómez Montero \\ Universidad Complutense de Madrid. Fundación Alberto Elzaburu \\ susogmontero@hotmail.com
}

Marca solicitada: MESSI (figurativa) vs. Marca oponente MASSI.

Inexistencia de riesgo de confusión.

Norma jurídica aplicada: Artículo 8.1 b) Reglamento de la Marca de la Unión Europea (RMUE).

Compatibilidad entre marcas cuando a pesar de ser visual y fonéticamente similares, al menos una de ellas posee un significado conceptual claro que lleva al público a diferenciarlas y no incurrir en confusión.

Relevancia derivada de la circunstancia de que la marca solicitada constituye el apellido de un célebre futbolista de fama mundial.

\section{Tramitación administrativa ante la EUIPO}

El 18 de agosto de 2011, Lionel Messi solicitó ante la Oficina de la Propiedad Intelectual de la Unión Europea (EUIPO) la marca

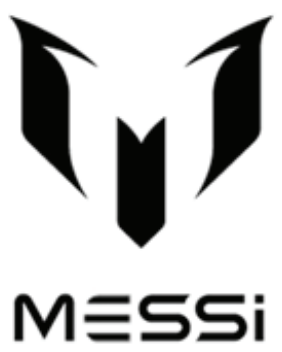


para distinguir los siguientes productos: aparatos e instrumentos de salvamento (clase 9); prendas de vestir, calzados y artículos de sombrerería (clase 25); artículos de gimnasia y deporte no comprendidos en otras clases (clase 28).

La solicitud fue objeto de oposición por parte del titular de las marcas de la Unión Europea (en la actualidad, J.M.-E.V. e hijos S.R.L.) constituidas por la denominación MASSI que distinguían los siguientes productos: prendas de vestir, calzados y artículos de sombrerería en clase 25 (MUE 3436607); cascos para ciclistas, trajes de protección contra los accidentes, dispositivos de protección personal contra accidentes en clase 9; y guantes para bicicleta, refuerzos protectores para hombros, codos y rodillas en clase 28 (MUE 414086).

La oposición fue estimada el 12 de junio de 2013. La resolución de la División de Oposición fue confirmada por la Sala de Recursos el 23 de abril de 2014 (R 1553/2013-1). Ambas instancias de la EUIPO entendieron que concurrían las circunstancias necesarias para aplicar el artículo 8.1. b) del Reglamento de la Marca de la Unión Europea (RMUE) pues, por una parte, los productos distinguidos por las marcas enfrentadas eran idénticos o similares y, por otra parte, las marcas resultaban semejantes porque sus elementos dominantes, constituidos por los términos "Massi" y "Messi”, eran prácticamente idénticos en los planos visual y fonético. Además, según la Sala de Recursos, una eventual diferencia conceptual entre ellas solo sería percibida, en su caso, por una parte del público pertinente y no podría enervar el riesgo de confusión derivado de las semejanzas seńaladas.

\section{La sentencia del Tribunal General}

Interpuesto el recurso por Lionel Messi, el Tribunal General (TG) lo estimó por sentencia de 26 de abril de 2018 (T-554/14). ${ }^{1}$ El TG, después de ratificar que los productos eran idénticos o similares, señaló que -al igual que lo manifestó la Sala de Recursos- los elementos dominantes de las marcas (las denominaciones MESSI/MASSI) eran semejantes visual y fonéticamente; sin embargo, estimó que, desde una perspectiva conceptual, había una clara diferenciación. El TG admite -aunque haya sido alegado por primera vez ante él- que la circunstancia derivada de la fama mundial y conocimiento del público del futbolista es un hecho notorio (hecho que cualquier persona puede conocer o que se puede averiguar por medio de fuentes generalmente accesibles) y que tal circunstancia influye decisivamente en la apreciación del riesgo de confusión que pudiera existir entre las marcas enfrentadas.

1 Véase: http://curia.europa.eu/juris/document/document.jsf?text=\&docid=201481\&pageI 
Según el TG, una parte significativa del público puede establecer una asociación conceptual entre el término "Messi" y el célebre jugador de fútbol, de modo que ese público percibirá de forma manifiesta la diferencia conceptual que existe entre las denominaciones MESSI y MASSI. La sentencia del TG concluyó afirmando que las diferencias conceptuales entre las marcas enfrentadas neutralizan las semejanzas visuales y fonéticas, de tal modo que no habrá entre ellas un riesgo de confusión que pudiera llevar al público a entender que los productos distinguidos por las marcas MESSI y MASSI proceden de la misma empresa o, en su caso, de empresas vinculadas económicamente.

\section{La sentencia del Tribunal de Justicia}

Tanto la EUIPO como el titular de la marca MASSI entablaron recursos de casación. Los recursos fueron desestimados por la sentencia de 17 de septiembre de 2020 (C-449-18 P y C-474/18 P) ${ }^{2}$ que inadmitió o desestimó los motivos planteados en ellos. Por una parte, el TJ indica que el carácter notorio o no de las circunstancias analizadas (apellido de personaje célebre) constituye una apreciación de naturaleza fáctica y, por tanto, no es susceptible de ser recurrido en casación. ${ }^{3}$ Por otra parte, el TJ reitera que, en realidad, el TG en su sentencia no introdujo un hecho nuevo al referirse a la notoriedad o celebridad de Messi en cuanto apellido del jugador de fútbol de fama mundial y en cuanto personaje público, pues era un hecho notorio, es decir, un hecho que cualquier persona podía conocer o que se podía averiguar por medio de fuentes generalmente accesibles, y estas fuentes eran elementos de los que podía disponer la Sala de Recursos cuando adoptó la resolución controvertida y que debería haber tenido en cuenta al apreciar la similitud entre los signos en cuestión en el plano conceptual.

El nudo de la cuestión principal del presente caso (relevancia del apellido Messi como determinante de la inexistencia del riesgo de confusión entre las marcas controvertidas) también es resuelto por el TJ en sentido favorable a las pretensiones del jugador. El TJ establece dos pautas básicas para analizar estos casos.

En primer término, el TJ proclama que debe tenerse en cuenta la posible notoriedad de la persona que solicita que su nombre se registre como marca, en la

ndex $=0 \&$ doclang=es $\&$ mode $=1$ st $\&$ dir $=\&$ occ $=$ first $\&$ part $=1 \&$ cid $=5300087$.

2 Véase: http://curia.europa.eu/juris/document/document.jsf?text=\&docid=201481\&pageI ndex=0\&doclang=es\&mode $=1$ st \&dir $=$ \&occ $=$ first \&part $=1$ \&cid $=5300087$.

3 Véase, en este sentido, el auto de 3 de junio de 2015, The Sunrider Corporation/OAMI, C142/14 P, no publicado, EU:C:2015:371, apartado 65 y jurisprudencia citada. 
medida en que tal notoriedad puede evidentemente influir en la percepción de la marca por el público pertinente. ${ }^{4}$

$\mathrm{Y}$, en segundo lugar, que la apreciación global del riesgo de confusión implica que las diferencias conceptuales entre dos signos pueden neutralizar las similitudes visuales y fonéticas entre ellos, siempre que al menos uno de tales signos tenga, en la perspectiva del público pertinente, un significado claro y determinado, de forma que ese público pueda captarlo inmediatamente. ${ }^{5}$

A ello añade el TJ que, a fin de apreciar si un signo tiene, desde la perspectiva del público pertinente, un significado claro y determinado, se pueden tener en cuenta tanto el signo relativo a la marca anterior ${ }^{6}$ como el signo correspondiente a la marca cuyo registro se solicita. ${ }^{7}$

Por ello, el TJ concluye afirmando que no existe riesgo de confusión entre las marcas enfrentadas debido, principalmente, a la celebridad y notorio conocimiento por el público de la persona del solicitante que se traslada lógicamente a la marca solicitada constituida por su apellido.

\section{Comentario}

La sentencia del TJ del caso Messi pone de manifiesto que la noción de la figura del riesgo de confusión es un concepto jurídico indeterminado que debe ser aplicado siempre en función del caso concreto que se esté analizando. En este sentido, podemos preguntarnos cuál habría sido la decisión si el caso a resolver fuera exactamente el contrario al enjuiciado, es decir, que la marca solicitada fuera MASSI, constituyendo MESSI la denominación de la marca oponente.

Seguramente, la decisión de los Tribunales sería aplicar el artículo 8.1 b) RMUE y declarar incompatibles las marcas enfrentadas debido a la evidente se-

4 Véase, en este sentido, la sentencia de 24 de junio de 2010, Becker/Harman International Industries, C51/09 P, EU:C:2010:368, apartado 37.

5 Véanse, en este sentido, las sentencias de 12 de enero de 2006, Ruiz-Picasso y otros/OAMI, C361/04 P, EU:C:2006:25, apartado 20; de 23 de marzo de 2006, Mülhens/OAMI, C206/04 P, EU:C:2006:194, apartado 35; de 15 de marzo de 2007, T.I.M.E. ART/OAMI, C171/06 P, no publicada, EU:C:2007:17, apartado 49; de 18 de diciembre de 2008, Les Éditions Albert RenélOAMI, C16/06 P, EU:C:2008:739, apartado 98; y de 9 de julio de 2015, Pêra-Grave/OAMI, C249/14 P, no publicada, EU:C:2015:459, apartado 39).

6 Véase, en este sentido, la sentencia de 12 de enero de 2006, Ruiz-Picasso y otros/OAMI, C361/04 P, EU:C:2006:25, apartado 27.

7 Véase, en este sentido, la sentencia de 9 de julio de 2015, Pêra-Grave/OAMI, C249/14 P, no publicada, EU:C:2015:459, apartados 39 a 44. 
mejanza visual y fonética entre los elementos MASSI/MESSI y la concurrencia de la identidad o similitud entre los productos distinguidos. Sin embargo, si seguimos los criterios sentados en la sentencia del caso MESSI y en la jurisprudencia europea citada en esta, la conclusión es otra: a pesar de las semejanzas visuales y fonéticas, no hay riesgo de confusión por la diferenciación conceptual y, por tanto, no resultaría aplicable el artículo 8.1 b) RMUE.

Creo que la doctrina sentada por el TJ en el caso Messi puede resultar perjudicial para la protección de las marcas de renombre (aquellas que son conocidas en alto grado por la generalidad del público o por un sector relevante de este), ya que tal conocimiento de la marca puede implicar que el riesgo de confusión con ella, derivado de una semejanza con otra marca posterior, se vea alejado. Esta tesis -que en su momento fue mantenida en alguna sentencia del Tribunal Supremo español y otros órganos inferiores y que parecería hoy felizmente desterradapuede resurgir nuevamente si los criterios utilizados en el caso Messi son aplicados mutatis mutandis automáticamente en el análisis del riesgo de confusión cuando la marca anterior es una marca de renombre. Así, se podría mantener que el propio renombre y conocimiento del público de la marca anterior llevaría a que una nueva marca (semejante) no se confundiría con aquella.

Por este motivo, es necesario encontrar una vía efectiva que desemboque en la protección de la marca de renombre más allá de la aplicación de las normas referentes al riesgo de confusión. Por eso, y volviendo al supuesto anteriormente planteado (solicitud de marca MASSI y oposición de marca MESSI), aunque se considerase inaplicable el artículo 8.1. b) RMUE, ello no debería implicar que la marca MASSI fuera concedida, ya que, en tal caso, se podría invocar la aplicación del artículo 8.5 RMUE que, precisamente, protege a la marca de renombre.

Si partimos de la base de que al apellido Messi le alcanza un grado de notoriedad importante, ese mismo grado podría alcanzar a una eventual marca MESSI registrada, que, en ese caso, debería considerarse "marca de renombre". Así, teniendo en cuenta la semejanza existente entre MASSI y MESSI -y aunque el público no las confunda-, ese público podría establecer un vínculo entre ellas que podría llevar a un aprovechamiento de la fama y reputación de la marca anterior. Pero, como decía, esto no es más que un supuesto, en el que incluso podrían existir una variada gama de circunstancias como, por ejemplo, las que se podrían derivar del uso efectivo del nombre MESSI como marca, forma de empleo, productos o servicios para los que hipotéticamente se hubiera utilizado, etcétera.

En definitiva, y volviendo al principio del comentario, no cabe duda de que a la hora de analizar temas relativos al derecho de marcas, las circunstancias del caso concreto son las realmente relevantes para su enjuiciamiento y, por eso, los 
criterios objetivos que se puedan establecer -por ejemplo, en relación con el riesgo de confusión- no son más que pautas que pueden servir para fundamentar una decisión, pero no deben ser elevadas a la categoría de universalidad y aplicación automática, pues las verdaderamente relevantes derivan del caso concreto objeto de análisis. 